\title{
A MATRIX-BASED APPROACH TO INVESTIGATE THE GEOMETRICAL DEPENDENCIES BETWEEN NON-DRIVING- RELATED TASKS AND FUTURE VEHICLE CONCEPTS
}

\author{
Seebach, Niko (1,2); Rück, Marcel (1); Arlt, Frank (1); Bender, Beate (2) \\ 1: BMW AG; 2: Ruhr-University Bochum
}

\begin{abstract}
Caused by the technology of automated driving the user is temporarily released from driving and can perform non-driving-related tasks (NDRTs), such as sleeping or working. The aim of this paper is to describe the geometrical interdependencies between NDRTs and different vehicle types, to be able to integrate them in the geometric package of the early phase of the vehicle conception. To address the objective a literature based study of existing approaches for vehicle conception and NDRT-studies was carried out. Additionally interviews with $n=15$ experts from the automotive conception department and a databased analysis of $n=259$ vehicles was conducted. Based on these investigations 91 geometrical characteristics for NDRTs and vehicle types werde determined and combined through a matrix-based approach. By analysing the approach highly connected characteristics such as the torso angle were identified and equations were set up to describe the relations. The approach can be used for different NDRTs such as relaxing and working and different vehicle types such as sporty cars or SUVs in order to integrate them into the package.
\end{abstract}

Keywords: Conceptual design, Early design phases, Complexity, Non-driving-related tasks, Vehicle package

Contact:

Seebach, Niko

BMW AG

Total Vehicle - Geometrical Concept Design, Integration

Germany

Niko.Seebach@bmw.de

Cite this article: Seebach, N., Rück, M., Arlt, F., Bender, B. (2019) 'A Matrix-Based Approach to Investigate the Geometrical Dependencies between Non-Driving-Related Tasks and Future Vehicle Concepts', in Proceedings of the 22nd International Conference on Engineering Design (ICED19), Delft, The Netherlands, 5-8 August 2019. DOI: $10.1017 /$ dsi.2019.288 


\section{INTRODUCTION}

The interior design of a car highly depends on the anticipated activities of the driver during the ride. Therefore the introduction of automated driving causes a fundamental redesign. Automated driving temporarily releases the user from performing the driving task. Hence he or she gains time for nondriving-related tasks (NDRTs), such as sleeping, watching movies or working (Pfleging and Schmidt, 2015). Geometric space for performing these tasks needs to be considered in the early phase of the concept development of the vehicle and especially within the context of the design of the interior (Tzivanopoulos et al., 2015). The investigation of the collision free positioning of vehicle components with occupants takes place in the so called "package". Caused by the high number of potential NDRTs and their interdependencies with the geometrical vehicle concept, these investigations gain a considerable amount of complexity. In order to perform analyses in the package, it is of central importance to identify and present the relations between vehicle types designed for the driving task and future possible NDRTs.

\subsection{Motivation and context}

In the following section the motivation is discussed in detail to clarify the relevance of this contribution and to categorise the results more accurate in the scientific and industrial context. The degree of automation is categorised by the Society of Automotive Engineers (SAE) in six different levels of automation (SAE International J3016, 2016). Level 0 vehicles currently constitute the largest share of existing vehicles in the world. They are exclusively controlled by the driver and are not automated at all (Hirz and Walzel, 2018). The required attention of the driver and the maximum time allowed to return to the standard driving position decreases with increasing level of automation. In a level 5 vehicle all devices used to control the vehicle, for example the steering wheel, are optional. The time horizon for the realisation of level 4 vehicles is estimated to be 2025 and level 5 to be 2035 if available at all (Fraunhofer IAO and Horváth \& Partners, 2016). Figure 1 shows the human-machine - i. e. driver-vehicle-interaction under the influence of automated driving (Bubb et al., 2015).

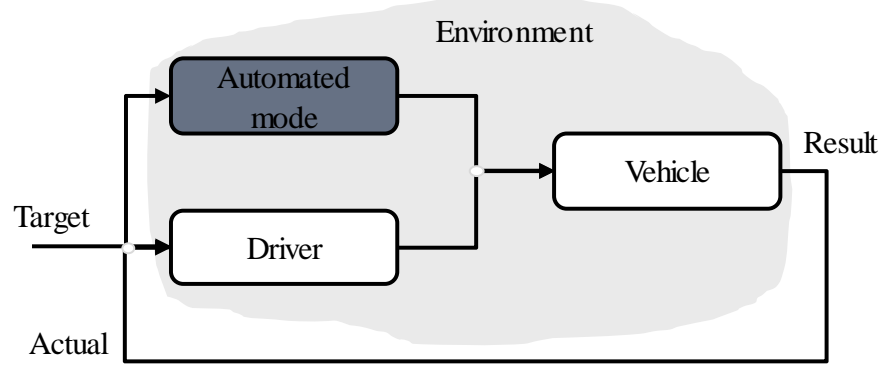

Figure 1. Human-Machine Interaction and influence of automated driving (Bubb et al., 2015)

In the automated mode of a level 4 or 5 vehicle the driver is decoupled from the loop and released from performing the driving task. Therefore all driving related tasks such as navigating, stabilizing, flashing, honking or wiping become obsolete. Only tasks which have nothing to do with the original driving task for example selecting a radio station or making a phone call are relevant for the definition of the design space for the driver in the automated mode. These activities are therefore defined as non-driving-related tasks (Pfleging and Schmidt, 2015). Additionally to the tasks already existing in level 1 vehicles new activities occur such as watching movies or working. The automation level investigated in this paper is level 4. In comparison to level 5 it can only be applied specified driving situations, which are influenced by external factors such as speed, weather, street-type or day-time. Hence there are driving situations where the automated mode is not availale and the driver has to perform the driving task. Therefore different car types, such as small, large and different shaped vehicles, designed for the original driving task as well as future potential NDRTs need to be considered in the geometrical package simultaneously, as shown in Figure 2. As shown in this example the driver performs the NDRT "relaxing" which leads to a geometrical inconsistency with regard to the second seating rows. The share of the travel time for performing these NDRTs will increase steadily or even exponentially the more driving situations are accessed by automated functions. This proves the high relevance of NDRTs for the interior design and has been investigated in several studies (Pfleging, 2017), (Fitzen et al., 2018). 

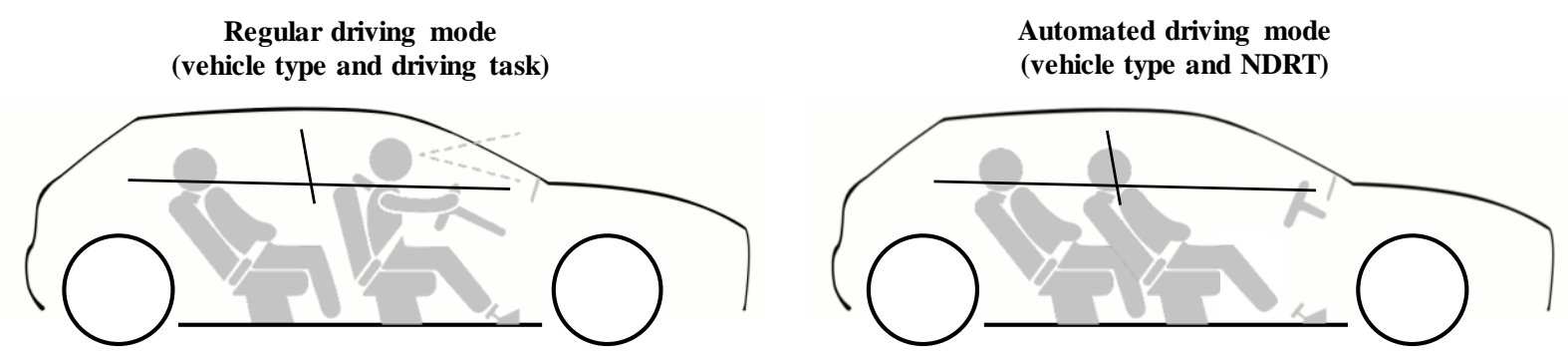

Figure 2. Regular- and automated driving mode in a level 4 automated vehicle

The reason to investigate into the geometrical interdependencies between vehicle type and NDRTs derives from the central importance of the concept phase of the product development process, which is described in various standard reference work like Pahl/Beitz (Pahl and Beitz, 2013). In this early phase of the product development process main geometrical characteristics of the product are determined. To also point out the relevance for the automotive industry, its specific product development process is described in the following paragraph. In this process the concept phase of a vehicle development consists of every task necessary, to create a consistent first draft of the anticipated vehicle (Pischinger and Seiffert, 2016), (Krasteva et al., 2017). The concept phase in the automotive product development process is part of the product definition phase. After this first phase the product genesis and the series support (life cycle) take part, as shown in Figure 3.

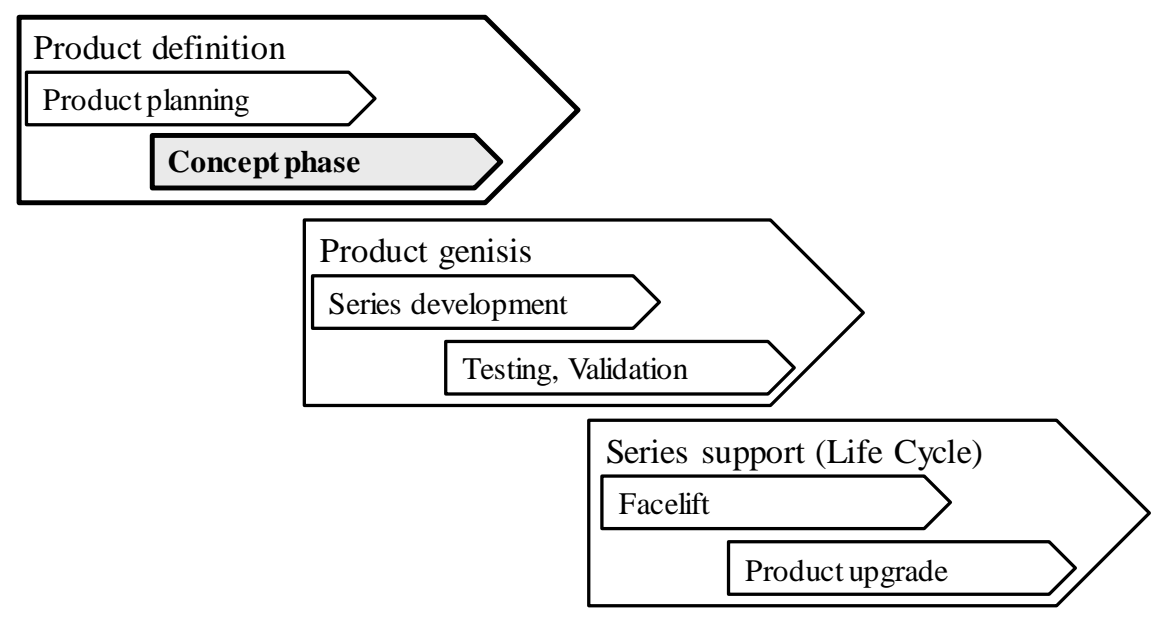

Figure 3. Automotive Product Development Process (Pischinger and Seiffert, 2016)

In the product definition phase, product planning is followed by the concept phase. The planning phase determines the main character and requirements of the vehicle based on input factors such as customer demands, study, brand image, market research, competition and trends. As an interface between the product planning and the concept phase goals are defined for the vehicle. The defined goals are then worked on by various departments and combined on the level of the total vehicle department. The geometric design, the package, plays an important role in the context of this early stage of development. In this phase a first technical concept is derived with specific dimensions of the occupants as well as the main car components such as engine, exterior, seats and trunk. The goal of the geometric package is to create a feasible first concept and position the mentioned components collision free. Currently the NDRTs are investigated by the product planning department by means of studies and market research.

However, within the concept phase there is no defined approach given on how to investigate the interdependencies between NDRTs and vehicle types. These approaches are of high interest because in this early concept phase a large part of costs for the vehicle is set. In an ongoing development process it becomes more and more complicated to adjust decisions that have been made earlier in the process. On the other side the knowledge about the anticipated product is rather low in the beginning of the development process so the decisions are taken on an uncertain basis. This correlation is described as the paradox of product development (Ehrlenspiel and Meerkamm, 2013). 


\subsection{State of research, research problem and goal}

In the current state of research there are approaches on how to integrate the driving task into different vehicle types. As an example a computer aided tool for the generation of consistent vehicle measure concepts and parametrical design demands is describe by Raabe (Raabe, 2013). The work is based upon a dependency matrix containing equations to show the relations between various vehicle dimensions. The limits of this approach are apparent when it comes to investigations for occupants not performing the driving task. The author points out that this would be an appropriate future step for research. Even in recent of research by Hahn this topic is still not addressed. The dependencies in this work between geometrical and functional characteristics are primarily derived by a statistical review of current vehicle types (Hahn, 2017). By using these statistical interdependencies, future vehicle concepts cannot be derived. Hence the work presented in this paper tries to close the gap between the NDRTs and the vehicle concept by investigating the interdependencies between vehicle types designed for the actual driving task and the NDRTs.

Therefore following research question was derived:

How can interdependencies between NDRTs and different vehicle types be determined and presented in order to support the product developer in the early concept phase of the product development process?

\section{METHOD}

In order to identify the interdependencies between different characteristics of a product, specifically a vehicle, two methods are used primarily. One method is the graph-based one which can be confusing and impractical when it comes to highly connected and complex structures, since the developer tends to forget dependencies or even characteristics. Furthermore the large number of connections between the characteristics are hardly traceable. An example for this problem can be found in the research of Prinz or Kuchenbuch who are both working in the field of vehicle conception and use a graph-based approach (Prinz, 2010), (Kuchenbuch, 2012). The other method is the matrix-based one which is proven to show clear relations between a large number of characteristics of products in general. Even domains and their complex structures can be represented (Warfield, 1973), (Steward, 1981), (Eppinger and Browning, 2012). In the research of vehicle conception this method has been used frequently and successfully (Raabe, 2013), (Krasteva et al., 2017), (Hahn, 2017). Therefore the matrix based method is chosen for the approach presented in this paper in order to show the interdependencies between NDRTs and vehicle types. Figure 4 shows the two methods in comparison. For this simple example the graph based representation seems to be easily traceable but a system with a large number of characteristics and dependencies can be confusing due to the large amount of connecting lines between the characteristics. For the matrix method however, even though a high number of characteristics leads to a larger matrix, the approach is more structured. Nonetheless the number of characteristics or parameters in a system should not be too high otherwise the system itself becomes not manageable (Lindemann, 2009). One solution is to cut off the less relevant parameters and focus on the more important ones or to create subsystems which contain a lower amount of parameters and are combinable with each other.

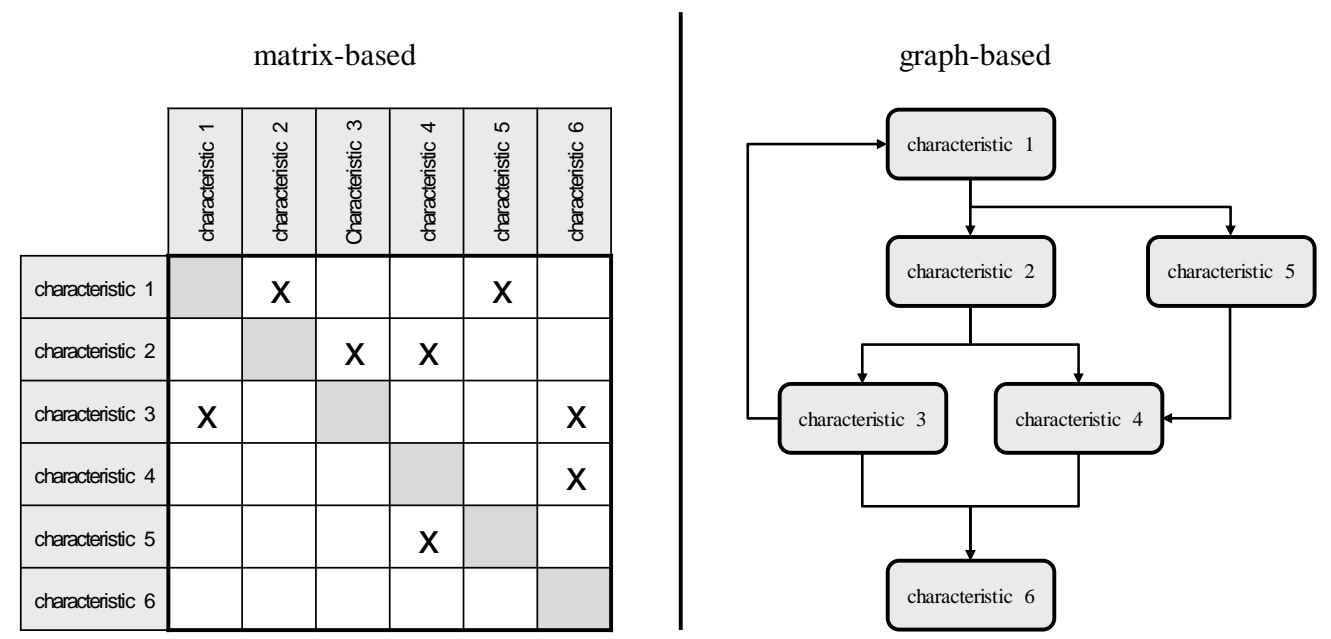

Figure 4. Matrix- and graph-based representation-method of interdependencies of product characteristics (Lindemann, 2009) 
In order to address the research question, three consecutive steps were conducted as shown in Figure 5. To begin with a literature based study of existing approaches for vehicle conception and NDRTstudies as well as a database evaluation of $n=259$ vehicle concepts were conducted in order set the main parameters for the system. The set of parameters contains on the one hand vehicle based characteristics such as vehicle length, width, height etc. and on the other hand user centric characteristics for the NDRTs such as hip angle, knee angle (Bubb et al., 2015), (Pischinger and Seiffert, 2016), (GCIE, 2018), (Seebach et al., 2018). For the second step an oral partial structured and open expert interview with $n=15$ experts from the automotive conception department was conducted in order to evaluate whether there is a connection between NDRT and vehicle characteristics or not. In case the experts anticipated a connection between characteristics, an equation needed to be found to mathematically describe the way they influence each other. In the third and final step the equations and characteristics were combined in an additional matrix. In this matrix the characteristics in the rows were replaced with the equations from the previous step. This way the developer obtains the opportunity to understand how specific characteristic of a NDRT influence characteristics of the vehicle concept by means of which defined equation. Additionally by analysing this matrix the characteristics that are highly interconnected and influence the vehicle concept most were detected by adding up in how many equations a characteristic was used.
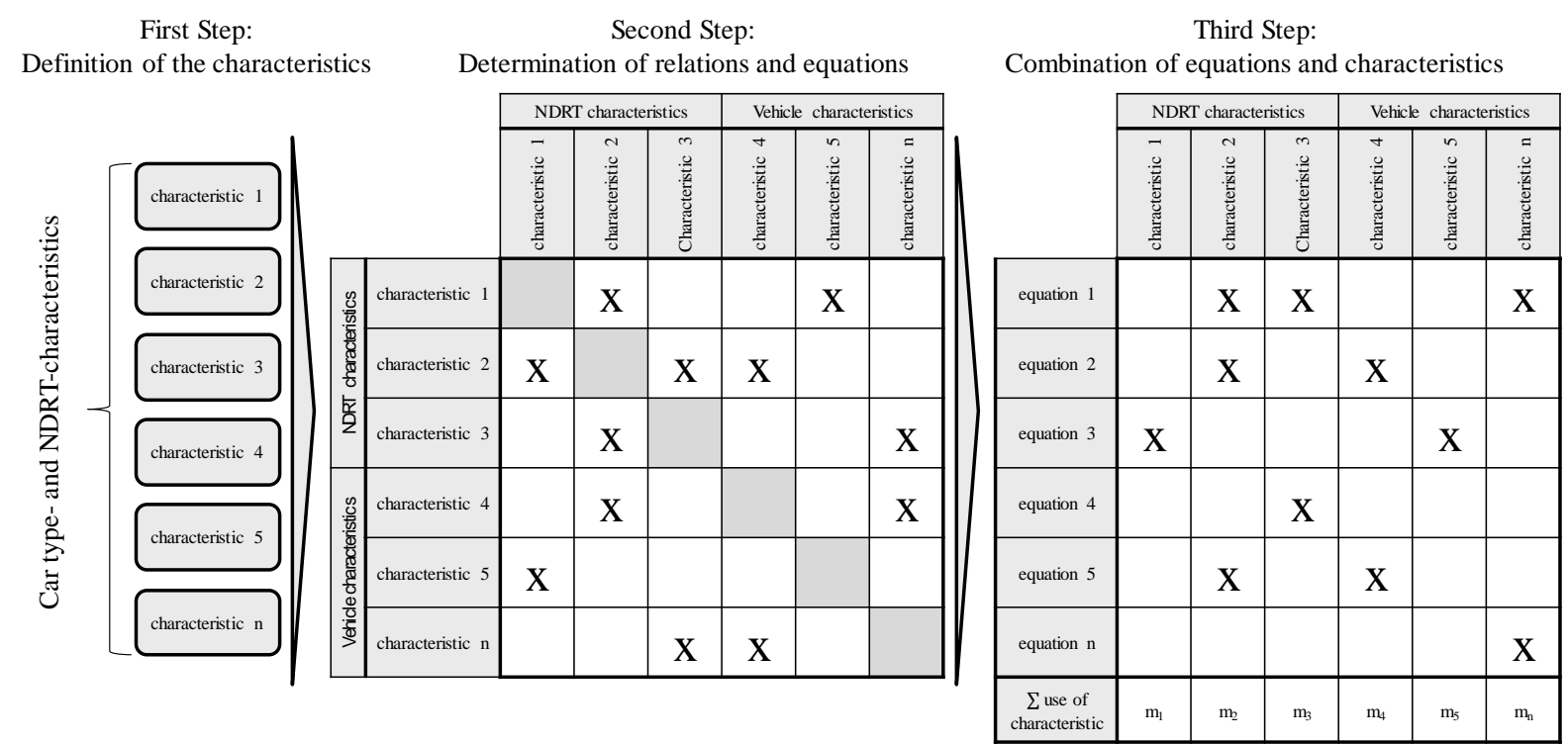

Figure 5. Approach and steps to identify the dependencies between NDRTs and vehicles

\section{RESULTS}

As a result of the first step overall 91 geometrical characteristics have been derived from the literature study, the databased evaluation and the expert interviews. 35 characteristics of them are user centric describing the NDRTs. 56 characteristics are related to the vehicle type and are based on the driving task. As a result of the second step the relations between the characteristics have been derived and a total of 75 equations have been established. The matrix of the last step gives the developer an overview in which equation the characteristics are contained. If the developer needs to gain further information on how a characteristic of an NDRT affects the vehicle concept the column of that characteristic must be examined. Each equation row affected is marked with an " $x$ ". Therefore information on how often a characteristic is connected in different equations can be received and additionally it can be directly investigated in the equation itself and seen in which way other characteristics are influenced if the decision is made to change that one specific parameter. Table 1 shows an excerpt of the whole matrix and how the different characteristics are contained in the equations. The analysis of the matrix reveals how often each parameter of the NDRTs is connected to each characteristic of the vehicle concept. Therefore in the following section the most important and highly connected parameters of the NDRTs and afterwards of the vehicle are described more detailed. 
Table 1. Excerpt of characteristics and equations of vehicle types and NDRTs

\begin{tabular}{|c|c|c|c|c|c|c|c|c|c|c|c|c|c|c|c|c|c|c|}
\hline & \multicolumn{11}{|c|}{ NDRT characteristics } & \multicolumn{7}{|c|}{ Vehicle characteristics } \\
\hline & 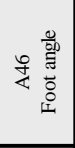 & 专卷高 & 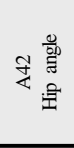 & 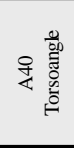 & 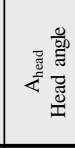 & 童 & 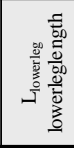 & 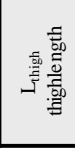 & 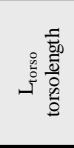 & 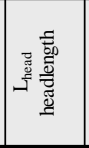 & 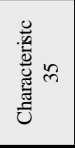 & 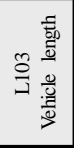 & 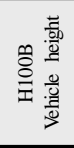 & 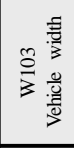 & 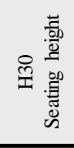 & O衰 & 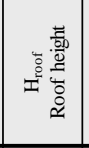 & 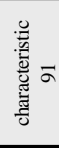 \\
\hline equation 1 & $\mathrm{X}$ & $\mathrm{X}$ & $\mathrm{X}$ & $\mathrm{X}$ & & $\mathrm{X}$ & $\mathrm{X}$ & $\mathrm{X}$ & & & & & & & & $\mathrm{X}$ & & \\
\hline equation 2 & $\mathrm{X}$ & $\mathrm{X}$ & $\mathrm{X}$ & $\mathrm{X}$ & & $\mathrm{X}$ & $\mathrm{X}$ & $\mathrm{X}$ & & & & & & & $\mathrm{X}$ & & & \\
\hline equation 3 & & & & $\mathrm{X}$ & $\mathrm{X}$ & & & & $\mathrm{X}$ & $\mathrm{X}$ & & & $\mathrm{X}$ & & $\mathrm{X}$ & & $\mathrm{X}$ & \\
\hline equation 4 & & & & $\mathrm{X}$ & $\mathrm{X}$ & & & & $\mathrm{X}$ & $\mathrm{X}$ & & $\mathrm{X}$ & & & & $\mathrm{X}$ & & \\
\hline equation 5 & & & & $X$ & & & & & & & & & & $\mathrm{X}$ & & & & \\
\hline equation 75 & & & & $\mathrm{X}$ & & & & & & & $\mathrm{X}$ & & & & & & & $\mathrm{X}$ \\
\hline $\begin{array}{c}\sum_{\text {charecteristic }} \\
\text { cic }\end{array}$ & $\mathrm{m}_{\mathrm{A46}}$ & $\mathrm{m}_{\mathrm{A} 44}$ & $\mathrm{~m}_{\mathrm{A} 2 \mathrm{2}}$ & $\mathrm{m}_{\mathrm{A} 40}$ & $\mathrm{~m}_{\text {Ahteaf }}$ & $\mathrm{m}_{\mathrm{L}_{\text {frot }}}$ & $\mathrm{m}_{\text {Llow }}$ & $\mathrm{m}_{\text {Lthigh }}$ & $\mathrm{m}_{\text {Ltorso }}$ & \begin{tabular}{|l|}
$\mathrm{m}_{\text {Lhead }}$ \\
\end{tabular} & $\mathrm{m}_{35}$ & $\mathrm{~m}_{\mathrm{L}, 133}$ & $m_{H 1100}$ & $\mathrm{~m}_{\mathrm{Y} V 103}$ & $m_{430}$ & $\mathrm{~m}_{\mathrm{G}}$ & $m_{\text {troof }}$ & $\mathrm{m}_{1}$ \\
\hline
\end{tabular}

First of all the most important parameter of the NDRTs is the torso angle. This parameter describes the angle between the vertical to the ground and the torsoline of the user. On the one hand, this parameter has a decisive influence on how other important angles such as knee- and hip angles are adjusted. On the other hand the torso angle is associated with almost any dimension in the X- or Z-direction, and even in the Ydirection, if rotation around the Z-axis is taken into account. In addition to the torso angle, the angles connected to large parts of the body such as the thighs and lower legs are other important parameters. In particular, the length of these body parts is also important as they are associated with the growth of the population. Smaller parts of the body such as the head or the feet are not connected as often as the other body parts. The additional free space required for the body parts also plays a minor role compared to the large extremities. Parameters describing the view of the passenger such as Y- or Z-view angle play a subordinate role in the equation system as most of the NDRTs are associated to elements that have a limited influence on the vehicle concept. The lowest contiguous parameters of NDRTs are those characteristics describing the accessibility of the user to control elements, since it is difficult to predict, where these elements are located and many of them are integrated into the seat.

The most important parameters of the vehicle are the big characteristics such as vehicle length, -height and -width and the wheelbase. These parameters are important since they contain the smaller parameters which can be substituted at any time. Due to this fact they are as important as any other highly connected characteristic, even though they are only connected in few equations. Smaller characteristics such as the roof height or the floor height are connected more often since they also can be substituted in the bigger equations. So every smaller equation can be traced back to one of the big dimensional equations. Another finding is that other big dimensional characteristics such as the overhang front (L104), describing the distance between front axle and front point of the bonnet, or the overhang rear (L105) describing the distance between rear axle and the last point of the rear, are rarely connected to the NDRTs, since they have a limited influence on the inner of the passenger cabin. It can be shown that characteristics that are somewhat close to the passenger itself have high relevance and large amount of connections to the NDRTcharacteristics.

An application example of the approach is shown by using the NDRT-characteristic of the torso-angle A40, as shown in Table 2. It is shown that the torso angle is contained in 21 equations and the first three equations are described in detail.

In case a specific value is assigned to this parameter A40, the influence on other parameters becomes clear and measurable. The first equation determines the G-measure which is defined as the length between the seating reference point and the ball of foot, as shown in Equation 1. Trigonometrical functions are used to extract the lenght component of the lower body parts in X-direction.

$$
\begin{aligned}
& G=\sin (A 46-(A 44-(A 42-A 40))) \cdot L_{F o o t}+\sin (\mathrm{A} 44-(\mathrm{A} 42-\mathrm{A} 40)) . \\
& \mathrm{L}_{\text {lowerleg }}+\sin (\mathrm{A} 42-\mathrm{A} 40) \cdot \mathrm{L}_{\text {thigh }}
\end{aligned}
$$


Table 2. Example of the influence of the torso angle A40 on vehicle dimensions

\begin{tabular}{|c|c|c|c|c|c|c|c|c|c|c|c|c|c|c|c|c|c|c|}
\hline & \multicolumn{11}{|c|}{ NDRT characteristics } & \multicolumn{7}{|c|}{ Vehicle characteristics } \\
\hline & 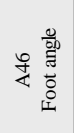 & 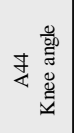 & 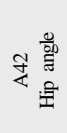 & 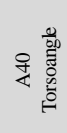 & 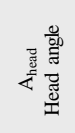 & 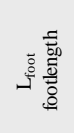 & 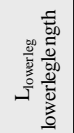 & 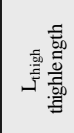 & 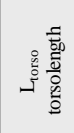 & 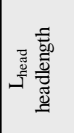 & 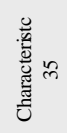 & 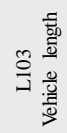 & 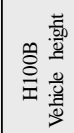 & 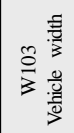 & 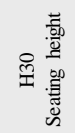 & O & 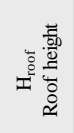 & 递 \\
\hline equation 1 & $\mathrm{X}$ & $\mathrm{X}$ & $\mathrm{X}$ & $\mathrm{X}$ & & $\mathrm{X}$ & $\mathrm{X}$ & $\mathrm{X}$ & & & & & & & & $\mathrm{X}$ & & \\
\hline equation 2 & $\mathrm{X}$ & $\mathrm{X}$ & $\mathrm{X}$ & $\mathrm{X}$ & & $\mathrm{X}$ & $\mathrm{X}$ & $\mathrm{X}$ & & & & & & & $\mathrm{X}$ & & & \\
\hline equation 3 & & & & $\mathrm{X}$ & $\mathrm{X}$ & & & & $\mathrm{X}$ & $\mathrm{X}$ & & & $\mathrm{X}$ & & $\mathrm{X}$ & & $\mathrm{X}$ & \\
\hline equation 4 & & & & $\mathrm{X}$ & $\mathrm{X}$ & & & & $\mathrm{X}$ & $\mathrm{X}$ & & $\mathrm{X}$ & & & & $\mathrm{X}$ & & \\
\hline equation 5 & & & & $\mathrm{X}$ & & & & & & & & & & $\mathrm{X}$ & & & & \\
\hline equation 75 & & & & $\mathrm{X}$ & & & & & & & $\mathrm{X}$ & & & & & & & $\mathrm{X}$ \\
\hline $\begin{array}{c}\sum_{\text {characteristic of }} \\
\text { che }\end{array}$ & $\mathrm{m}_{\mathrm{A} 46}$ & $\mathrm{~m}_{\mathrm{A44}}$ & $\mathrm{m}_{\mathrm{A} 42}$ & 21 & $\mathrm{~m}_{\text {Aheaf }}$ & $\mathrm{m}_{\text {Lffoot }}$ & $\mathrm{m}_{\text {Llow }}$ & $\mathrm{m}_{\text {Lthigh }}$ & $\mathrm{m}_{\text {LLorso }}$ & $\mathrm{m}_{\text {Lhead }}$ & $m_{35}$ & $\mathrm{~m}_{\mathrm{L} 103}$ & $\mathrm{~m}_{41100}$ & $\mathrm{~m}_{\mathrm{W} 103}$ & $\mathrm{~m}_{\mathrm{H} 30}$ & $\mathrm{~m}_{\mathrm{G}}$ & $\mathrm{m}_{\text {froof }}$ & $m_{1}$ \\
\hline
\end{tabular}

In Equation 2 the seating height is described which is defined as the vertical length between the seating reference point and the ball of foot, as shown in equation 2 . For this equation the same trigonometrical functions are used but this time to extract the lenght component of the lower body parts in Z-direction.

$$
\begin{aligned}
& H 30=\cos (A 46-(A 44-(A 42-A 40))) \cdot L_{F o o t}+\cos (\mathrm{A} 44-(\mathrm{A} 42-\mathrm{A} 40)) \cdot \\
& \mathrm{L}_{\text {lowerleg }}+\cos (\mathrm{A} 42-\mathrm{A} 40) \cdot \mathrm{L}_{\text {thigh }}
\end{aligned}
$$

The third equation describes the head room above the passenger in the front, as shown in Equation 3. This equation is an example of the usage of the $\mathrm{H} 30$ as a substitute for the whole Equation 2. Otherwise Equation 3 would be even longer and harder to understand. The equations consists of a substraction of different elements from the vehicle height such as the roof heigt.

$$
\begin{aligned}
& H_{\text {headspace }}=H 100 B-\left(H 30+H_{\text {roof }}+\cos (A 40) \cdot L_{\text {torso }}+\sin \left(A_{\text {head }}-\left(90^{\circ}-A 40\right)\right) \cdot\right. \\
& \left.\left.L_{\text {head }}\right)\right)
\end{aligned}
$$

\section{CONCLUSION AND OUTLOOK}

The result of this research gives an approach on how to investigate and transparently present the geometrical interdependencies between NDRTs and different vehicle types for a level 4 automated vehicle with the support of a matrix based representation of characteristics and equations. The basis for filling the matrix was a literature based study, a databased analysis of $n=259$ vehicles and an expert interview with $\mathrm{n}=15$ experts from the concept development department. Based on the findings the developer gains mandatory information for the early concept phase. First of all it is shown which characteristics are of high importance in the early development stage. In addition it is also demonstrated which characteristics interact which each other and how they interact in terms of geometrical equations. Also further information is given by representing how often each parameter of vehicle types and NDRTs is connected. With the support of this approach the developer can integrate the NDRTs into the package of the early concept development phase of future level 4 automated vehicles. The applicability of the approach was tested by an exemplary application of the specific characteristic torso angle.

For future research the later phases of the development process also need to be investigated by using additional characteristics and equations for a subsystem described on a more detailed level. Additionally the connection to other functional parameters or characteristics need to be examined. An automated application of the matrix would also be supportive for using the findings. In future research a connection of the matrix based approach to a CAD-system which also contains a human model needs to be implemented. By means of this connection the equations and characteristics become more transparent and can be shown in three-dimensional CAD-model. As an example the influence of the torso-angle can be visually shown much more easily with the support of this CAD-model than with the exclusive description of the 
equations. The presented approach will be implemented in the early concept phase of vehicle development and applied to different NDRTs and vehicle concepts. In order to evaluate and validate the approach, various NDRTs such as sleeping, working or watching movies and different vehicle types such as sporty vehicles or SUVs will be used in the concept phase of future level 4 automated vehicles.

\section{REFERENCES}

Bubb, H., Bengler, K., Grünen, R.E. and Vollrath, M. (2015), “Automobilergonomie, ATZ / MTZ-Fachbuch, Springer Vieweg”, Wiesbaden. http://dx.doi.org/10.1007/978-3-8348-2297-0.

Ehrlenspiel, K. and Meerkamm, H. (2013), "Integrierte Produktentwicklung: Denkabläufe, Methodeneinsatz", Zusammenarbeit, Vol. 5., überarb. und erweiterte Aufl., Hanser, München, Wien. http://dx.doi.org/10.3139/9783446436275.

Eppinger, S.D. and Browning, T.R. (2012), Design structure matrix methods and applications, Engineering systems, MIT Press, Cambridge Mass. u.a.

Fitzen, F., Seebach, N., Amereller, M. and Paetzold, K. (2018), "Nutzerorientierte Charakterisierung fahrfremder Tätigkeiten in automatisierten Fahrzeugen”, Krause, D., Paetzold, K., Wartzack, S. (Hg.), DfX-Symposium, TuTech Verlag, Tutzing.

GCIE (2018), “Global Cars Manufacturers Information Exchange Group: GCIE Procedure Part 3. Package Drawing Exchanges. Model Year 2018".

Hahn, J. (2017), "Eigenschaftsbasierte Fahrzeugkonzeption: Eine Methodik in der frühen Konzeptphase", AutoUni - Schriftenreihe, Vol. 108, Springer, Wiesbaden, Germany. http://dx.doi.org/10.1007/978-3-65820101-2.

Hirz, M. and Walzel, B. (2018), "Sensor and object recognition technologies for self-driving cars", ComputerAided Design and Applications, pp. 1-8. http://dx.doi.org/10.1080/16864360.2017.1419638.

Krasteva, P., Tzivanopoulos, T., Vietor, T. and Inkermann, D. (2017), "Zielkonfliktidentifikation zwischen Design, Technik und Ergonomie - Ein Beitrag zur Lösungsfindung am Beispiel der PKWMaßkonzeption", in Stuttgarter Symposium für Produktentwicklung SSP 2017: Stuttgart, 29. Juni 2017, Wissenschaftliche Konferenz, Universität Stuttgart.

Kuchenbuch, K. (2012), "Methodik zur Identifikation und zum Entwurf packageoptimierter Elektrofahrzeuge, Zugl.: Braunschweig, Techn. Univ.”, Diss., 2012, AutoUni-Schriftenreihe, Vol. 25, Logos-Verl., Berlin.

Lindemann, U. (2009), Methodische Entwicklung technischer Produkte, Springer Berlin Heidelberg, Berlin, Heidelberg. http://dx.doi.org/10.1007/978-3-540-37451-0.

Pahl, G. and Beitz, W. (2013), Pahl/Beitz Konstruktionslehre: Methoden und Anwendung erfolgreicher Produktentwicklung, 8., vollständig überarbeitete Auflage, Springer Vieweg, Berlin, Heidelberg. http://dx.doi.org/10.1007/b137606.

Pfleging, B. (2017), “Automotive user interfaces for the support of non-driving-related activities", Universität Stuttgart. http://dx.doi.org/10.18419/opus-9090.

Pfleging, B. and Schmidt, A. (2015), “(Non-) Driving-Related Activities in the Car: Defining Driver Activities for Manual and Automated Driving", Workshop on Experiencing Autonomous Vehicles: Crossing the Boundaries between a Drive and a Ride, No. CHI'15.

Pischinger, S. and Seiffert, U. (Eds.) (2016), Vieweg Handbuch Kraftfahrzeugtechnik, ATZ / MTZ-Fachbuch, 8., aktualisierte und erweiterte Auflage, Springer Vieweg, Wiesbaden. http://dx.doi.org/10.1007/978-3-65809528-4.

Prinz, A. (2010), "Struktur und Ablaufmodell für das parametrische Entwerfen von Fahrzeugkonzepten”, Dissertation, Technische Universität Carolo-Wilhelmina zu Braunschweig, Berlin, 2010.

Raabe, R. (2013), "Ein rechnergestütztes Werkzeug zur Generierung konsistenter PKW-Maßkonzepte und parametrischer Designvorgaben, Zugl.: Stuttgart, Univ.”, Diss., 2013, Bericht / IKTD, Institut für Konstruktionstechnik und Technisches Design, Universität Stuttgart, Vol. 614, Inst. für Konstruktionstechnik und Techn. Design, Stuttgart.

SAE International J3016 (2016), "Surface Vehicle Recommended Practice. Taxonomy and Definitions for Terms Related to Driving Automation Systems".

Seebach, N., Fitzen, F., Arlt, F. and Bender, B. (2018), “Geometrische Beschreibung fahrfremder Tätigkeiten”, Krause, D., Paetzold, K., Wartzack, S. (Hg.), DfX-Symposium, TuTech Verlag, Tutzing.

Steward, D.V. (1981), "The design structure system. A method for managing the design of complex systems", IEEE Transactions on Engineering Management, Vol. EM-28 No. 3, pp. 71-74. http://dx.doi.org/10.1109/TEM.1981.6448589.

Tzivanopoulos, T., Watschke, H., Krasteva, P. and Vietor, T. (2015), "Neue Denkansätze in der Fahrzeugkonzeption”, ATZ - Automobiltechnische Zeitschrift, Vol. 117 No. 9, pp. 16-21. http://dx.doi.org/10.1007/s35148-015-0101-y.

Warfield, J.N. (1973), "Binary Matrices in System Modeling”, IEEE Transactions on Systems, Man, and Cybernetics, Vol. SMC-3 No. 5, pp. 441-449. http://dx.doi.org/10.1109/TSMC.1973.4309270. 